\title{
The competitive environment of academic productivity and the academic research enterprise in the case of Japan
}

\author{
Akira Arimoto
}

Received: 26 October 2008/Revised: 30 December 2008/Accepted: 7 January 2009/Published online: 24 April 2009

(C) The Author(s) 2009. This article is published with open access at Springerlink.com

\begin{abstract}
This article deals with the various problems related to the given title from four sections. Section "Social function of the academic research enterprise (ARE)" focuses on three problems: Framework of the research on the ARE; Functions of the graduate school in the ARE; and Centers of learning and Japanese ARE. Section "Structure of ARE" discusses two problems: Structure of social stratification and the structure of ARE in the policy framework for the current ARE. Section "Social condition of ARE" argues over three problems: Social condition of the ARE; The effects of change of national policy on the ARE; and National government policy for the ARE in the postwar period. Section "The impacts of the national government policies on ARE" treats three problems: Trend of the recent national government policy on the ARE; Some unintended effects of the policies; and Discussion of proposals for reform. These discussions lead to concluding remarks.
\end{abstract}

Keywords Academic productivity .

Academic research enterprise (ARE) - Graduate school . National government policy

\section{Introduction}

The main purpose of this article is directed to realize the present situation and problems related to Japanese academic research enterprise (ARE) from a sociological

\footnotetext{
A. Arimoto $(\square)$

Research Institute for Higher Education, Hijiyama University, 4-1-1, Ushita Shinmachi, Higashi-ku, Hiroshima 732-8509, Japan

e-mail: arimoto@hijiyama-u.ac.jp
}

approach which is consisted of three parts such as social condition, social function, and social structure.

First, the Social condition means a social environment surrounding academia which is composed of three factors such as knowledge function, social change, and national government policy. There is a mutual interaction between these three parts, and the effects from these parts to academia mean social conditions and reverse effects from academia to these parts mean social function. For example, "knowledge reconstruction" makes effects on four academic works consisting of research, teaching, service, and administration and management, which are formed on the basis of knowledge function. Accordingly, study of ARE is necessary to take account of these knowledge functions of research, teaching, service, and administration and management, especially research.

In addition to knowledge function, it is necessary to pay attention to social change and national government policy which effect on ARE through academia. Social change comprises such great changes as globalization, marketization, knowledge-based orientation of society, which has necessarily caused academia's reform and innovation so as to cope with such changes.

Second, social function of academia, especially ARE, is an intimate relationship with research, teaching, service, and administration in knowledge functions. Among these, the significance of research together with teaching is considered to be most important in academic work. Due to its contribution to the development of society as well as to learning, the academic research function is accorded the highest esteem. Now the university with graduate school is expected to contribute to learning through research as a core of ARE. Academic productivity, especially research productivity as well as teaching productivity, is considered to be an important indicator to acknowledge prestige and 
reputation of activities in the graduate schools. From an international comparison of such academic productivity, we can recognize a social stratification of academic systems, institutions, and organizations. In such social stratification of academic systems, Japanese academic system has developed rapidly from a peripheral status to a part of the center of learning in the world. Why is it possible to construct such position in short term after the institutionalization of modern higher education in the late nineteenth century?

Third, the structure of ARE is focused on the question of how to make social stratification of ARE in a Japanesedifferentiated society in academia with the separation of national, public, and private sectors together with that of research university and non-research university. The structure of ARE is also focused on the policy framework for the current ARE, analyzing of public financing of research in the university sector and policies connecting academic research to economic development.

Fourth, the national government policy is significant for the development of ARE as mentioned above. The effects of change of national policy on ARE in the prewar period and the postwar period are also important factors to understand the traits intrinsic to Japanese ARE. A series of national governmental policies have many effects on ARE directly and indirectly through academia to the extent that they make the characteristics of ARE proper to Japan.

The relation between the national policy for science and technology and the national policy for the higher education system and its reform has extended over more than a century. In this context, current university reforms, including reform of the ARE, show recognizable trends. From a perspective of knowledge reconstruction, a great impact of science and technology has brought about university reforms. The effects of the importance of knowledge development and construction of intelligence have caused expectations of higher education and development of human resources. From a perspective of social change, the demands of globalization and a knowledge-based economy have been heightening expectation through the international competition on and between institutions, and the needs of knowledge-based society has been demanding for university reforms.

These observations lead to an analysis of the impacts of the national government policies on ARE today, accompanying some unintended effects of the policies. The national government proposed new academic research policies successively in 1998 and 2004, promoting the priority accorded to the research university and its graduate education. As a result, several negative sides as well as positive sides are recognizable in relation to the national academic research policies so as to form a competitive Japanese ARE in an international competitive environment.

\section{Social function of the ARE}

Framework of the research on the ARE

This article seeks to analyze the themes related to the ARE. It is necessary to consider at least three sociological approaches: social condition, social structure, and social function (Arimoto 2003). Among these, the social condition derives from the effects of social change on ARE from three sources.

\section{Social condition}

Knowledge function. The first source is the knowledge function: knowledge and academic work on the basis of knowledge are considered as the major determinants of university structure and function. A series of studies in the sociology of science have tried to approach academic work in relation to the function and production of knowledge in the scientific and academic community (Merton 1973; Light 1974; Spiegel-Rosing and de Price 1977; Shinbori 1985; Becher 1981, 1989; Arimoto 1987, 1996; Gibbons et al. 1994; Becher and Trowler 2001; Bleiklie and Henkel 2005; Parry 2007). Academic work with regard to learning, research, teaching, and service, basically consists of the knowledge function: application of knowledge, scientific knowledge, academic discipline, etc. The function of knowledge largely comprises five parts: understanding, discovery and invention, dissemination, application, and control of knowledge. Accordingly, in the study of ARE, much attention should be paid to these functions, even though ARE mainly emphasizes the knowledge functions of research.

\section{Social change}

The second source is a social change such as globalization, marketization, knowledge-based orientation of society, which has major effect as social pressure by shaping academia's reform and innovation so as to respond to such change. As discussed later in this article, a series of national governmental policies for ARE as well as the university are reflections of these social changes.

\section{National governmental policy}

The third source is the series of national government policies, which have many effects on ARE as well as the university and which effectively make the characteristics of ARE intrinsic to each individual country, though they are also influenced directly by the social changes. The section three deals with the national government policy on ARE. 


\section{Social structure and function}

The social structure of ARE refers to society internal to ARE itself including the structure of its social power, prestige, and hierarchy. The social function of ARE is connected to the function of knowledge previously mentioned, because ARE works on the basis of the research function of knowledge.

Functions of the graduate school in ARE

The university was originally thought to be an institution contributing to development of knowledge by treating it as a matter of importance. It is clear that academia is expected to develop the function of knowledge, to contribute to scientific development and through this to contribute to societal development, as it is an enterprise uniquely based on knowledge as its raw material (Clark 1983). Accordingly, an inevitable problem for academia is to ensure the quality of its academic work, situated as it is at the core of its knowledge function. Knowledge has its own functions consisting of discovery, dissemination, application, and control; or, expressed in other words, research, teaching, service, and management, respectively. Among these, the significance of research together with teaching is considered to be most important. Due to its contribution to the development of society as well as to learning, the academic research function is accorded the highest esteem.

For many years after the institutionalization of the university in society, university education was assumed to constitute the major purpose of higher education. Yet the commitment of teachers as well as students to research has become increasingly strong since the modern university was established in the nineteenth century. Now the university is expected to contribute to learning through research. The graduate school, invented in the U.S. in the nineteenth century, has subsequently become a central component of centers of learning throughout the world (Clark 1993, 1995). The concept of the graduate school was imported to Japan during the postwar period with the introduction of a two-tier system of undergraduate and graduate levels. Graduate schools, considered to be a core of ARE, have been gradually institutionalized in higher education institutions throughout the country to a considerable extent. A core part of the research university is substantially formed of graduate schools.

\section{Centers of learning and Japanese ARE}

A study of academic productivity, a concept derived from that of scientific productivity used by Merton (1973), is inevitable because the main role of the ARE is to raise the academic productivity (Arimoto 2007). Over time, as the logic of academic productivity suggests, study of the centers of learning has been developed since Ben-David introduced this concept (Ben-David 1977). In his study, Japan was identified as located on the periphery of the centers of learning in the 1960s but subsequently it has progressed gradually from the periphery toward the center.

Japanese universities, which started as modern universities after the Meiji Restoration in 1867, have developed gradually, reaching the level of other advanced countries within a century. That they could enter the core group of advanced countries in terms of academic productivity is indicated-amongst other criteria-by the number of publications, Science Index Citations (SCI), Nobel laureates, and patents. There remain doubts that Japan has yet to reach a status comparable to that of Europe and the U.S.

Japan was perhaps the nation where performance in science and technology (comes) closest to Europe and the United States, but even there competitiveness in basic science remained modest even under its most successful period as an economic superpower in the 1970s and 1980s although Nobel Prizes were high on the research policy wish list, and some were also received. (Sorling and Vessuri 2007, p. 5).

Nevertheless, it is clear that Japan has gained considerable quality and reputation after starting from a far weaker position than Europe and North America.

As is shown in Fig. 1, which deals with changes over time in the number of published papers among scientists worldwide, Japan is placed in a group with three other countries, the U.K., Germany, and France, which lags far behind the U.S. as far as these indicators are concerned. Japan's share of published papers, for example, amounts to $10.2 \%$ of 735,000 in 2002, while the U.S.'s contributes $32.0 \%$.

Of the scientific papers published in major scientific journals around the world between 1981 and 2005, Japan's share of scientific papers and citations was as shown in Fig. 2. Japan's share of scientific papers in 1981 was fourth in the world, after the United States, the United Kingdom, and Germany. However, ever since Japan surpassed the United Kingdom in 1990 to obtain the No. 2 ranking, Japan has maintained its position at No. 2. Moreover, since excellent papers tend to attract large numbers of citations in other papers, the number of citations can be viewed as one indicator of a paper's quality. A look at the number of citations of papers authored by Japanese researchers through the year 2005 by year of publication reveals that Japan's share of total citations has tended to rise over time. Nevertheless, Japan has ranked after the United States, the United Kingdom, and Germany in the number of citations ever since 1990, and the ratio to total citations remains much lower than the share of the total number of scientific papers published (Fig. 2) (MEXT 2007, p. 139). 
Fig. 1 Selected countries' shares of published papers for Scientific Information (National Science Indicators, 1981-2002) (percentage). Source: Institute

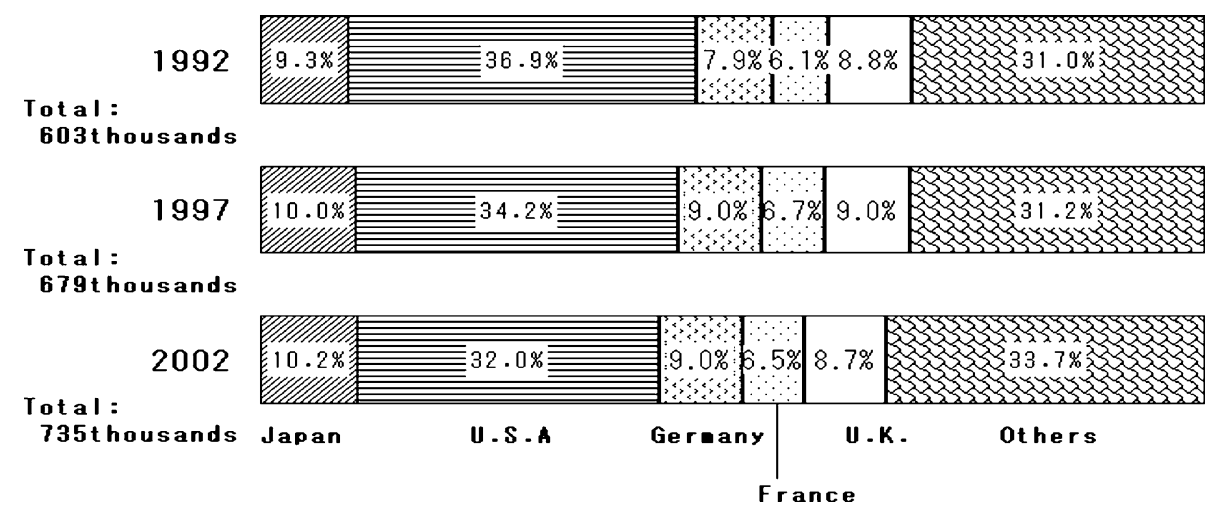

Fig. 2 Relationship between the world total for scientific papers and for citations in scientific papers. (1) The figures for Russia include those for the Soviet Union. (2) The figures for Germany include those for the former East Germany. Source: Collected by the Ministry of Education, Culture, Sports, Science and Technology based on "National Science Indicators, 1981-2005" (Thomson Scientific)

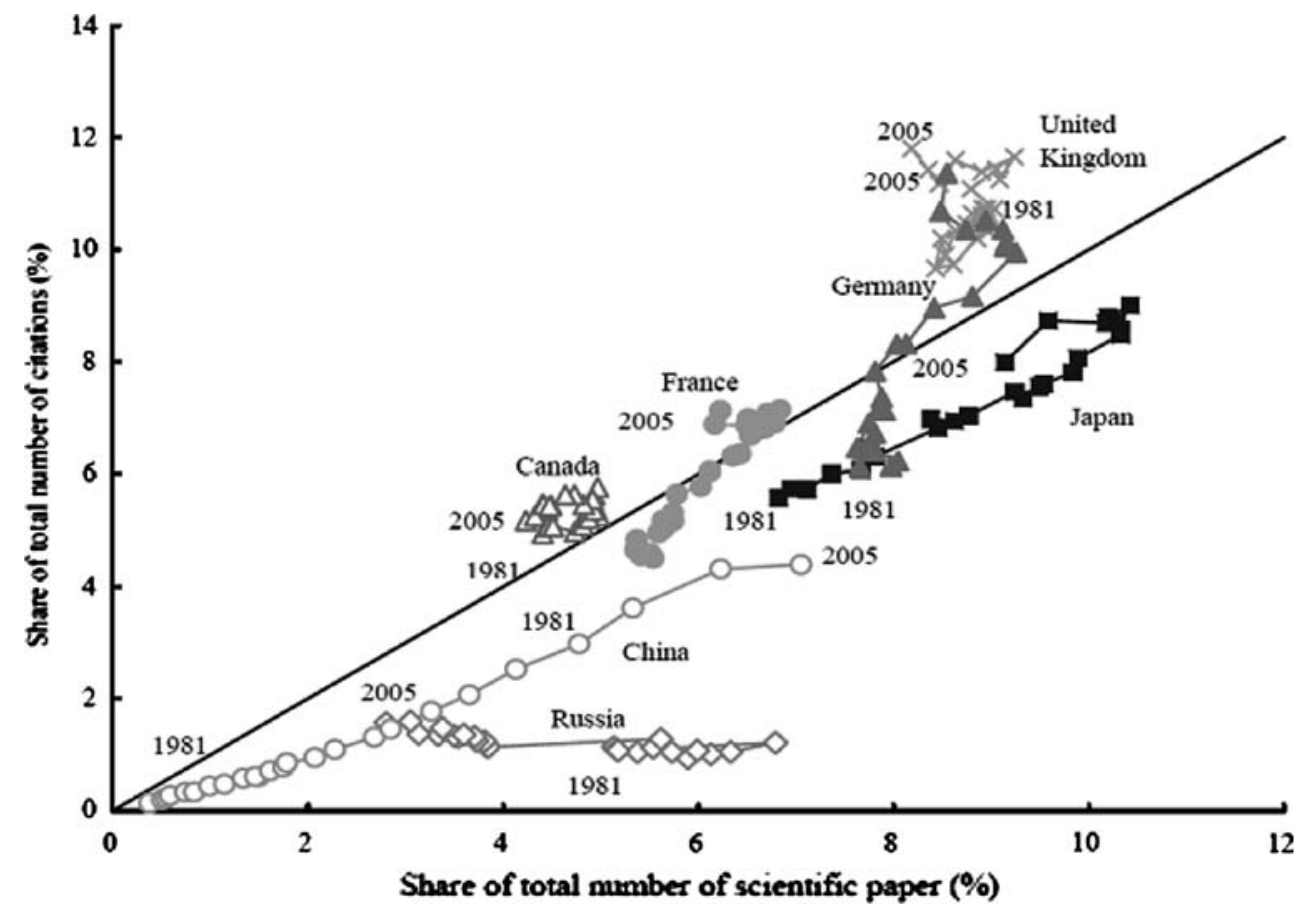

Of course, Japanese government is paying attention to quality side of academic productivity such as Science Citation Index (SCI) and Relative Citation Impact (RCI), and recognized the necessity of much more improvement to catch up with the advanced countries.

The RCI shows the number of citations per scientific paper from Japan divided by the number of citations per scientific paper for the world as a whole. Japan's RCI value is less than 1.0, putting it in a position relatively lower than other major selected countries. Where the RCI for Japan and the United States has stayed relatively stable since 1981, it has risen in the other major countries, with particularly strong increases seen in recent years for the United Kingdom, Germany, and France (Fig. 3) (MEXT 2007, pp. 139-140).

However, according to Masayuki Kobayashi's analysis on Academic Ranking of World Universities which Shanghai Jiao Tong University reported in its survey in 2004, it is clear that Japan is ranked at the top four after the U.S., the
U.K., and Germany in terms of the distribution of top 200 universities by country (Fig. 4). In this ranking of top 200, as many as 90 universities are occupied by the U.S., followed by 18 by the U.K., 17 by Germany, 9 by Japan and Canada, 8 by France, 7 by the Netherlands, and 6 by Sweden and Switzerland. If we see the distribution by area in top 50, ranking is North America $(37 ; 74 \%)$, Europe $(11 ; 22 \%)$, and Asia and Pacific $(2 ; 4 \%)$ in this order. As for top 200, majority is also occupied by North America with 99, or $49.5 \%$, followed by Europe with 79 , or $39.5 \%$, Asia and Pacific with 21 , or 10.5\%, and Latin America with 2, or 1.0\% (Kobayashi 2005, pp. 21-23). In the picture of prevailing North America and Europe, Asia and Pacific and other areas occupy small portions. Japan is leading outside of North America and Europe.

It is not unexpected that the series of scientific policies should have yielded significant effects on academic productivity and its status in the world scientific community. One of the most effective policies in recent years has been 
Fig. 3 Trends in the relative citation impact for scientific papers in selected countries. Source: Collected by the Ministry of Education, Culture, Sports, Science and Technology based on "National Science Indicators, 1981-2005"

(Thomson Scientific) (MEXT 2007)

Fig. 4 Distribution of top 200 by country (Kobayashi 2005, p. 23)
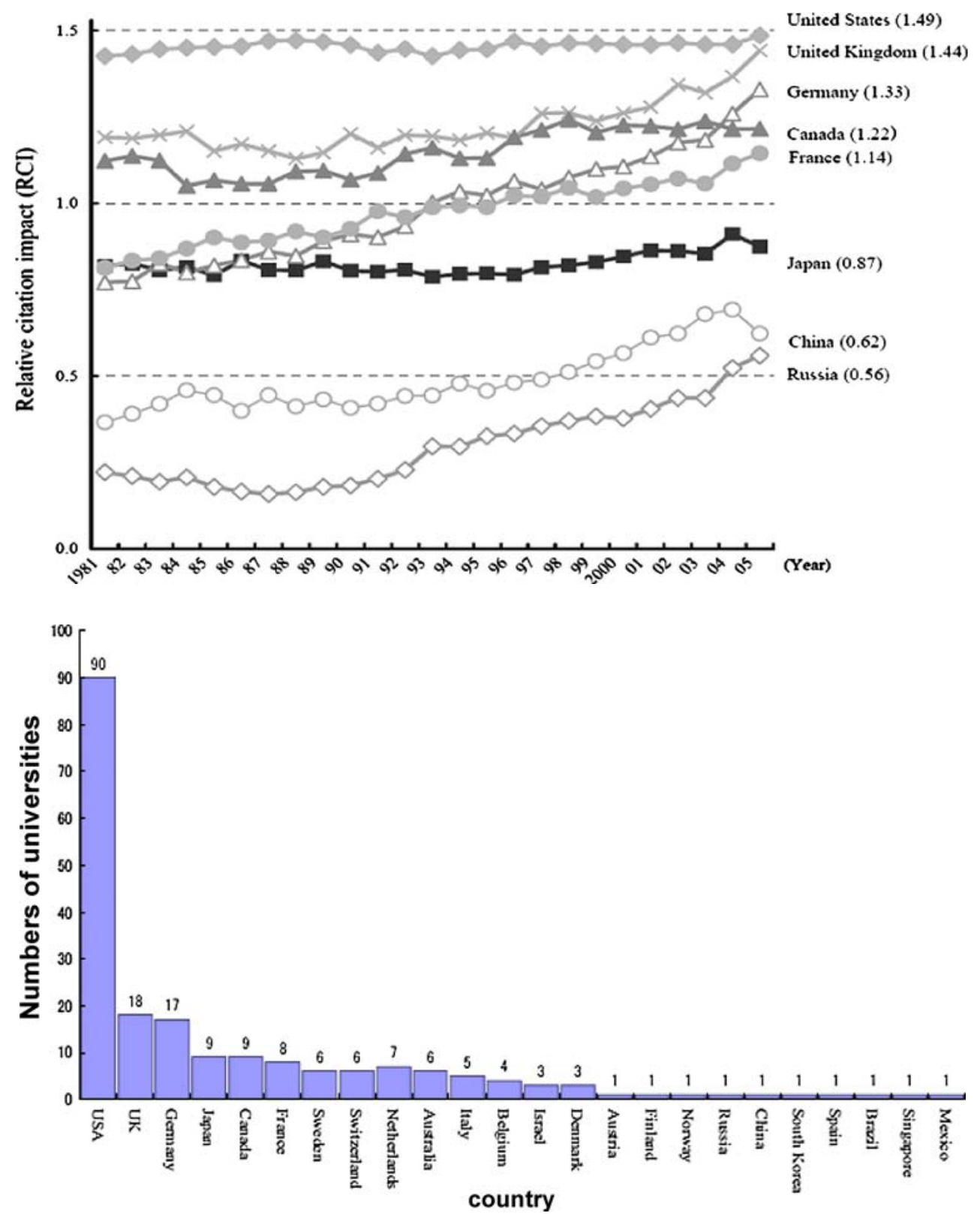

the Science and Technology Basic Plan, which was introduced in 1996 and is described below: it can be seen to have been fundamental to the development of ARE.

\section{Structure of ARE}

Structure of social stratification

\section{Relation among national, public, and private sectors}

A major factor in the achievement of the present status, resulting from the process of catching up with other advanced countries in regard to academic productivity, probably lies in the traits of the present structure of ARE. These are derived from the social stratification in which the national sector prevails. The higher education institutions in Japan can be grouped into three sectors, national, public, and private. As the Table 1 focusing on university shows that the private sector quantitatively occupies a majority share of the market with $553(76.2 \%)$ of the total of 726 institutions as of 2005. The national sector with $87(12 \%)$ and the public sector with 86 (12\%) provide smaller shares. As far as ARE is concerned, the share of the private sector is still high, with 282 (68.9\%) of the total of 409 doctoral courses. There is though a somewhat different image if we view it from a qualitative perspective. It is universities in the national sector that enroll and graduate a large majority (70\%) of doctoral students. 
Table 1 Number of universities by sector
Note Figures in parentheses refer to those providing regular courses as well as correspondence courses (MEXT 2007)

\begin{tabular}{|c|c|c|c|c|c|}
\hline & \multicolumn{5}{|c|}{ Universities } \\
\hline & Total & National & Local & Private & $\begin{array}{l}\text { Percentage } \\
\text { of private }(\%)\end{array}$ \\
\hline 1955 & 228 & 72 & 34 & 122 & 53.5 \\
\hline 1960 & 245 & 72 & 33 & 140 & 57.1 \\
\hline 1965 & 317 & 73 & 35 & 209 & 65.9 \\
\hline 1970 & 382 & 75 & 33 & 274 & 71.7 \\
\hline 1975 & 420 & 81 & 34 & 305 & 72.6 \\
\hline 1980 & 446 & 93 & 34 & 319 & 71.5 \\
\hline 1985 & 460 & 95 & 34 & 331 & 72.0 \\
\hline 1990 & 507 & 96 & 39 & 372 & 73.4 \\
\hline 1995 & 565 & 98 & 52 & 415 & 73.5 \\
\hline 2000 & 649 & 99 & 72 & 478 & 73.7 \\
\hline 2001 & 669 & 99 & 74 & 496 & 74.1 \\
\hline 2002 & 686 & 99 & 75 & 512 & 74.6 \\
\hline 2003 & 702 & 100 & 76 & 526 & 74.9 \\
\hline 2004 & 709 & 87 & 80 & 542 & 76.4 \\
\hline 2005 & 726 & 87 & 86 & 553 & 76.2 \\
\hline \multicolumn{6}{|l|}{ (Recounted) } \\
\hline \multicolumn{6}{|l|}{ Universities providing: } \\
\hline Evening courses & 115 & 35 & 8 & 72 & 62.6 \\
\hline Master's courses & 540 & 87 & 71 & 382 & 70.7 \\
\hline Doctor's courses & 409 & 75 & 52 & 282 & 68.9 \\
\hline Professional degree courses & 92 & 27 & 3 & 62 & 67.4 \\
\hline $\begin{array}{l}\text { Universities providing programs } \\
\text { by correspondence and mass media }\end{array}$ & (32) 35 & - & - & (32) 35 & 100.0 \\
\hline $\begin{array}{l}\text { Graduate schools providing programs } \\
\text { by correspondence and mass media }\end{array}$ & (17) 19 & - & - & (17) 19 & 100.0 \\
\hline
\end{tabular}

The numbers of $\mathrm{PhDs}$ graduating from the national sector are much greater than that from the private sector, especially in the field of natural sciences. In 2005, new entrants to doctoral courses numbered 17,553, of which $11,937(68.0 \%)$ were enrolled in the national sector, 4,525 $(25.7 \%)$ in the private sector, and 1,091 (6.2\%) in the public sector (Table 2). Incidentally, the gender these students enrolled in are categorized as male, 12,407 (70.7\%) and female 5,146 (29.3\%). Male students belong to national sector with 8.689 (70.0\%); public sector with 727 (5.9\%); and private sector with 2,991 (24.1\%), while female students belong to national sector with 3,248 (63.1\%); public sector with 364 (7.0\%); and private sector with $1,534(29.8 \%)$. The courses they enrolled in are categorized as humanities, 1,621 (9.2\%); social science, 1,571 (8.9\%); science, 1,621(9.2\%); engineering, 3,359 (19.1\%); agriculture, 1,057(6.0\%); health, 5,696 (29.0\%); home economics, $94(0.5 \%)$; education, $410(2.3 \%)$; fine arts and music, 183 (1.0\%); and others, 1,941 (11.1\%).

As a result, in terms of the research enterprise, the national sector substantially occupies the center of learning in Japanese higher education.

\section{Research universities}

Hegemony of the national university is also testified in the fact that a greater share of the group of research universities is occupied by the national universities. The term "research university" (kenkyu daigaku) was originally used by the Carnegie Classification in U.S. (Carnegie Commission on Higher Education 1976). It was introduced into Japan in the early 1980s when Ikuo Amano first applied the classification to AREs of Japanese higher education institutions (Amano 1984, pp. 57-69). At that time, the number of research universities amounted to 24 (15 national, 4 public, and 5 private institutions), which is $5.4 \%$ of the then total of 443 universities (Amano, ibid., p.71). If it can be assumed that a similar proportion of the now 726 universities can be similarly categorized as research universities, the number in 2005 would be 39, though current estimates yield a somewhat smaller number. The situation also seems to be true in 2008 when 765 (86 national; 90 public; and 589 private) universities would be 41 , though reality is likely to be a somewhat smaller number (Cf. MEXT 2008). 
Table 2 New entrants to graduate school: doctor's course

\begin{tabular}{lrrrr}
\hline & Total & National & Local & Private \\
\hline 1955 & 902 & 714 & 24 & 164 \\
1960 & 2,223 & 1,571 & 172 & 480 \\
1965 & 3,551 & 2,346 & 405 & 800 \\
1970 & 3,336 & 2,170 & 177 & 989 \\
1975 & 4,158 & 2,547 & 253 & 1,358 \\
1980 & 4,669 & 2,830 & 265 & 1,574 \\
1985 & 5,877 & 3,582 & 343 & 1,952 \\
1990 & 7,813 & 5,170 & 417 & 2,226 \\
1995 & 13,074 & 9,244 & 677 & 3,153 \\
2000 & 17,023 & 11,931 & 941 & 4,151 \\
2001 & 17,128 & 11,989 & 1,012 & 4,127 \\
2002 & 17,234 & 11,966 & 1,029 & 4,239 \\
2003 & 18,232 & 12,386 & 1,144 & 4,702 \\
2004 & 17,944 & 12,230 & 1,129 & 4,585 \\
2005 & 17,553 & 11,937 & 1,091 & 4,525 \\
Male & 12,407 & 8,689 & 727 & 2,991 \\
Female & 5,146 & 3,248 & 364 & 1,534 \\
Humanities & 1,621 & 709 & 94 & 818 \\
Social science & 1,571 & 667 & 122 & 782 \\
Science & 1,621 & 1,354 & 123 & 144 \\
Engineering & 3,359 & 2,662 & 134 & 563 \\
Agriculture & 1,057 & 907 & 37 & 113 \\
Health & 5,696 & 3,818 & 439 & 1,439 \\
Mercantile marine & - & - & - & - \\
Home economics & 94 & 31 & 27 & 36 \\
Education & 410 & 282 & 2 & 126 \\
Arts & 183 & 64 & 25 & 94 \\
Others & & 1,443 & 88 & 410 \\
\hline Source: & & &
\end{tabular}

Source: MEXT (2006)

One reason why the national research enterprise is so well developed is due to the history of higher education over the past century. The national government has concentrated resources on universities in the national sector, especially on the research universities and in the fields of science, engineering, agriculture and-in particular-health.

A relatively small number of national universities have shown great initiative in raising academic productivity. In fact, on the basis of the Academic Ranking of World Universities that Jiao Tong University issued we can recognize six national universities (University of Tokyo, 20th; University of Kyoto, 22nd; University of Osaka, 67th; University of Tohoku, 76th; University of Nagoya, 94th; and University of Tokyo Kogyo, 99th), five of which belong to the category of former imperial universities (Teidai), are ranked in the top 100 in 2007 (Jiao Tong University 2007). Neither private universities nor public universities are ranked in the top 100. It is this outcome that has been accelerated so rapidly by recent academic policies, which have been directed toward sustaining the past achievements of the research universities, and now have gradually extended differentiation between the research and non-research universities.

\section{Hierarchy of higher education system}

The hierarchy of the higher education system was originally created politically and deliberately from the start of the modern higher education system in Japan (Amano 1986). It has been constantly maintained through the postwar era notwithstanding the process of massification of higher education. There are status gaps between the national and private sectors, the research and non-research university sectors, key- and non-key institutions, and between individual research universities (the former imperial universities and others). Reflecting this policy, culture and climate, many institutions have chosen to pay much attention to the research function of the university, while giving less attention to its teaching function. There are also many gaps internally between an institution's research orientation and a lack of teaching orientation (Altbach 1996; Arimoto and Ehara 1996).

The structure of ARE in the policy framework for the current ARE

Before discussing the trend of national governmental policies on the ARE, it is useful to consider the current structure of ARE in respect to some traits in the policy framework.

\section{Public financing of research in the university sector}

National policy for higher education in the postwar period emphasized reliance on private expenditure by restricting public expenditure. As a result, government expenditure on higher education as a proportion of gross domestic product (GDP) remained as small as $0.5 \%$, which is lower than that of other advanced countries in OECD. On the other hand, private expenditure on higher education amounts to $2.0 \%$ of GDP, which is equivalent to that of the U.S. and higher than that in the advanced countries of Europe (Arimoto 2005b). However, while the limitations implied by these statistics have been long known, they have changed little over the years.

Amount of allocation in the various indicators The University Council (UC) and Central Education Council (CEC) regularly pointed out that the level of national expenditure on higher education was among the smallest of advanced countries (UC 1998; CEC 2005). In fact, if we look at the trend of government-financed $R \& D$ expenditure (i.e., the share of $R \& D$ expenditures financed by government), in FY 2004 Japan ranked lowest of a group of selected countries: France (37.6\%), EU-25 (35.7\%), EU-15 (34.0\%), Germany (30.4\%), U.K. (32.8\%), U.S. (31.0\%), 
and Japan (19.0\%) (MEXT 2007; the same source is used for data quoted in the following paragraphs).

The distribution of Japan's R\&D expenditures by performance sector in 2004 was as follows: government research institutions (7.7\%), universities and colleges $(19.1 \%)$, industry $(71.4 \%)$, and private research institutions (1.7\%); restricted to only the natural sciences (which includes engineering, technology, and medical science) the distribution is $9.1 \%, 13.2 \%, 75.8 \%$, and $1.9 \%$, respectively. The relative proportion and absolute level of $R \& D$ expenditure provided by industry is high. In universities and colleges in 2005, R\&D expenditures per researcher varied according to the sector: national sector, $¥ 22.56$ million; other public sector, ¥14.40 million; and private sector, ¥17.84 million (MEXT 2006, 2007).

The R\&D expenditures by character of the work show greater expenditures on development than on basic and applied research: in Japan in 2005, the proportions were basic research, 14.3\%; applied research, 22.8\%; and development, $62.9 \%$. Similar recent statistical data for the U.S. (in 2004, basic research, 18.7\%; applied research, $21.3 \%$; and development, 60.0\%), France (in 2003, basic research, 24.1\%; applied research, 36.2\%; and development, 39.7\%) and Germany (in 1993, basic research, 20.7\% and applied research/development, 78.8\%). These results show that all countries except Japan spend more on basic research. This fact is a persisting trend in almost 25 years from 1981 to 2005 (Fig. 5). (Ibid.)

In this context, it is interesting to point out that all the four Japanese Nobel Laureates, Yoichiro Nanbu, Makoto Kobayashi, Toshihide Masukawa, and Osamu Shimomura, who were awarded in 2008, made their discoveries being matched for Nobel Prize more than 35-50 years ago in the field of basic research of physics and chemistry. This fact probably suggests, under the recent low basic research expenditure as shown in Fig. 5, that possibility of producing Nobel Laureates in future will be restrained to a considerable degree.
Allocation processes: competitive allocation by project, institutional block grant, and performance-based funding Those research universities with high research achievement are now allocated much higher funding. As described previously, "research universities" are restricted to a small number in all universities and colleges. The category of research university in 2006 identifies approximately $4 \%$, or 30 institutions, among the total of 744 fouryear universities and colleges throughout Japan. Among these 30 institutions, the number of research universities in each sector can be roughly estimated as follows: a group of former imperial universities, 7; a group of other national universities, 10; a group of public universities, 3; and a group of private universities, 10 .

By source of funding for R\&D expenditures at universities and colleges in FY 2005, the government accounted for about $50 \%$ of the total (which includes the full costs of academic and support staff). The total R\&D expenditures at universities and colleges had increased by $4.1 \%$ over the previous fiscal year to $¥ 3,407,4$ billion, accounting for about $20 \%$ (19.1\%) of Japan's total R\&D expenditures. For trends in R\&D expenditures by university sector, national and private universities registered year-on-year increases: in 2005, the total expenditures were private sector, $¥ 1,732.2$ billion; national sector, $¥ 1,490.4$ billion; and other public sectors $¥ 184.8$ billion. Similarly, all fields of study within the natural sciences registered year-on-year increases to give the following totals: health sciences, $¥ 893.0$ billion; engineering, ¥769.3 billion; physical sciences, $¥ 349.0$ billion; and agricultural sciences, $¥ 141.4$ billion (MEXT 2007).

Investment of funds and resources in key areas in natural sciences was seen to be more advantageous than in other areas. So, in the twenty-first century COE program, which was started in 2002, much more weight was put on provision of resources to the field of natural sciences, including health sciences, engineering, physical sciences,
Fig. 5 Trends in the proportion of basic expenditures in selected countries. Source: Japan, United States-same as in Fig. 2-1-3. Germany, France-OECD. "Research and Development Statistics" (MEXT 2007)

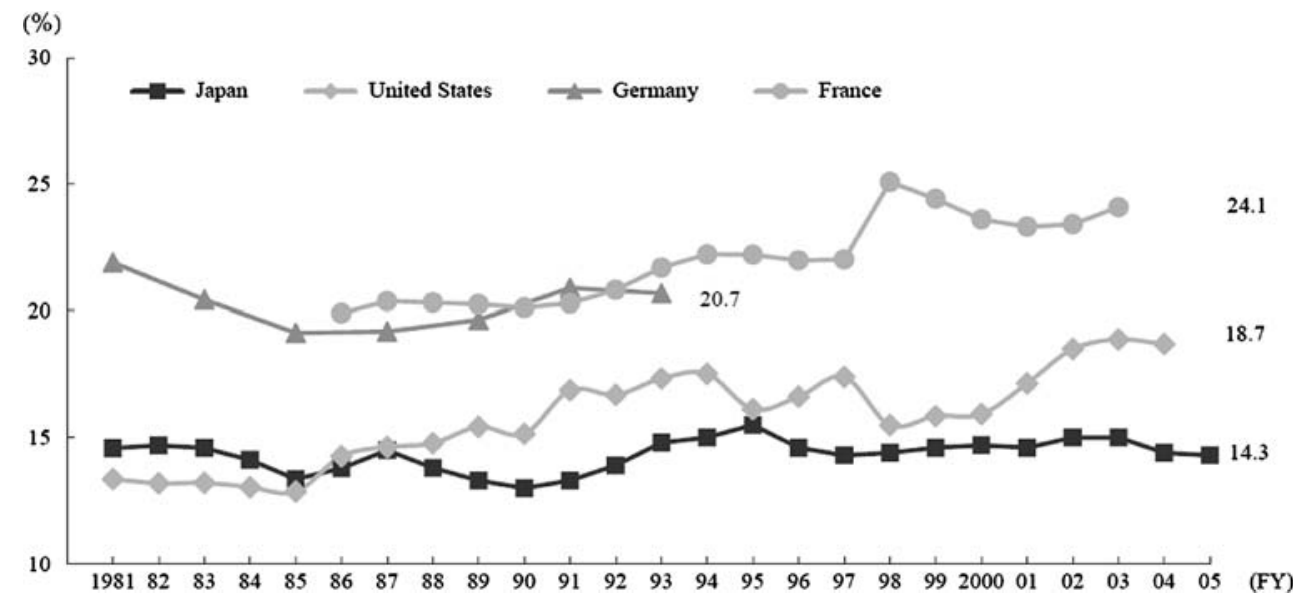


and agricultural sciences, than to the field of humanities and social sciences.

\section{Policies connecting academic research to economic development}

Subsidies for joint research ventures between universities and industry Until 20 years ago, linkages between university and society in Japan were largely non-existent: there was a kind of taboo forbidding this among people inside academia. This climate was created at the time of the campus turmoil that prevailed from the 1960s to the early 1970s and lasted more or less until around the 1980s. During this period, many companies invested research funds in foreign research universities, especially those in the U.S. rather than in their counterparts in Japan. Recently, however, in Japan, all universities have begun attempts to strengthen the linkages between university and society.

Programs encouraging contact and communication between university researchers and their counterparts in business and industry The recent situation of the Japanese innovation system is indicated by the following sequence of legislation: 1998, the Law for Promoting University-Industry Technology Transfer; 1999, the Industrial Revitalization Law (partly modeled on the U.S. Bayh-Dole Act); 2000, the Industrial Technological Ability Strengthening Law (allowing national university professors and other staff to hold appointments in private companies while retaining their university employment (cf. Rissanen and Viitanen 2001).

Various kinds of linkages are now under development to reform the structures for disseminating information and for research exchanges aimed at strengthening coordination among industry, academia, and government. In recent years, universities have begun to extend their activities beyond generating the seeds that are the source of knowledge to include university start-ups to develop new goods and services on the basis of their own research results. The number of university-based ventures in 2000 was 128 and in 2005, 1,141 (MEXT 2006).

Policies maintaining effective research doctoral education The present situation for national research grants and fellowships for research doctoral students is briefly described below. The Japan Student Service Organization (JASSO) offered scholarships to 1,091,607 students at a cost of $¥ 788.8$ billion in 2006 ; in 1998 , the comparable numbers were 499,121 students and $¥ 266.5$ billion (JASSO 2006). Both numbers of students and costs have continuously increased over these 8 years. The numbers of fellowships for research doctoral students in graduate schools have also been increased to some extent. The program of the Japan Society for the Promotion of Science (JSPS) intensively supports graduate students in their research and so contributes greatly to development of academic research. "The growing need to foster young researchers who will play an important role in future scientific research activities is recognized by JSPS through two special programs under which fellowships are granted to (1) young Japanese postdoctoral researchers to conduct research activities at Japanese universities or research institutions on a non-employment basis and to (2) graduate students who conduct research in Japanese university doctoral programs. The fellowship recipients may apply for a research grant of up to $¥ 1,500,000$ yen per year. If it becomes necessary to advance their work, they may, for a stipulated period of time, conduct research at other research institutions including those overseas" (JSPS 2007).

National fellowships are available for studies both in the natural sciences and in the humanities and social sciences. However, provision for doctoral students does not cover all the necessary costs and entails many difficulties during their period of training as researchers. In 2000, doctoral students in the national, public, and private sectors on average received the following levels of income: total income, ¥2.73 million, consisting of $¥ 0.53$ million (19\%) from family, ¥0.89 million (33\%) from scholarships, $¥ 0.68$ million ( $25 \%$ ) from part time jobs, and $¥ 0.63$ million (23\%) from permanent jobs and other sources. Their average expenditure is $¥ 2.73$ million, consisting of $¥ 0.74$ million for tuition charges and fees, and $¥ 1.51$ million $(67 \%)$ for living expenses (Council of Science, Engineering, and Human Resources 2002). In 2007, annual expenditure of doctoral students is 2.1569 million consisting of 0.46 million for tuition, 0.307 million for other fees, 0.1589 million for study, 0.346 million for extra activities, 0.34 million for travel expenses, 0.421 million for food, and 0.4733 million for residence and utilities (Keidanren 2007).

\section{Social condition of ARE}

\section{Social condition of ARE}

Globalization has many aspects: "Globalization encompasses global financial markets, growing global interconnectedness, global and regional trade agreements, media, information systems, labor markets, telecommunication, etc." (Maassen and Cloete 2006, p. 16). It is likely to emphasize global interconnectedness, integration, centralization, and standardization of education as well as culture, and be challenging to higher education systems by bringing 
about more or less monoculturization of all systems worldwide. Especially, the trend that enables WTO/GATS to view education as a commodity has become a source of pressure leading to global standardization of higher education (Arimoto 2002, 2005a). With its connection to globalization, marketization became dominant worldwide in the fields of politics and economy in the 1980s, developing gradually over time into the domain of culture and education (Arimoto 2002, 2005a).

In addition to these social changes, there are other important changes including an orientation to lifelong learning, a declining population (NIPSSR 2004), and economic retrenchment as external pressures on Japanese universities and colleges. How to respond to these pressures to implement academic reforms is of increasing public interest and expectation, because outcomes of the reforms are expected to affect directly and indirectly the development of society as well as the development of learning.

The effects of change of national policy on ARE

By focusing on the current situation in Japan, this section attempts to discuss the effects of reform of national research policy on the ARE. It is noteworthy that three distinctive stages, the prewar-, postwar- and the contemporary-eras, are recognizable in terms of the relevant developmental stages relating to this theme. The brief consideration of the characteristics of the prewar-era is based on a previous article (Arimoto 2007).

\section{Introduction of advanced models into Japan}

Science and technology were introduced to Japan from the advanced western countries as a means of catching up with developments already established overseas to modernize Japan as swiftly as possible by introducing advanced models of higher education. In the process of importing advanced models, selection of then strong models was intensively and carefully done to the extent it was fairly successful in introducing the most advanced models of sciences and academic disciplines in nineteenth century. Shigeru Nakayama pointed, for example, the following specific characteristics particular to advanced countries (Nakayama 1978, p. 43). Mechanics, commercial law, geology, iron manufacturing, architecture, shipbuilding, stock farming, etc., are strong in the U.K.; International law, biology, census, astronomy, mathematics, physics, chemistry, etc., are strong in France; Politics, Economics, Physics, Astronomy, geology, chemistry, biology, medicine, school law, etc., are strong in Germany; water supply, architecture, shipbuilding, politics, economics, etc., are strong in the Netherlands; mail system, industrial arts, agriculture, stock farming, commercial law, mine, etc., are strong in the U.S. Fortunately, Japan was not colonized by the western countries so that no culture and academic disciplines were enforced like many Asian countries.

\section{Creation of the national identity}

Implementation of advanced western models into its system confronted Japan with significant conflicts. Accordingly, Japan was led to create its own model of higher education. This became especially evident in the postwar years. Over more than 60-year span of the postwar period, a persistent and intense search for a national identity or Japanese model for the higher education system, was pursued, particularly by examining two dominant models: the German and the American. Some of the current higher education reforms, largely based on the American model of higher education, have failed in spite of the endeavors to institutionalize it having been continued over half a century (Amano 2006).

\section{From the periphery to a $C O E$}

In general, Japan has successfully caught up with advanced models to the extent that it has reached the level of other centers of learning, or centers of excellence (COE), by penetrating the barrier from the periphery of learning in the sense described by Ben-David in the 1970s (Ben-David 1977). This is evidently true in the field of natural sciences and engineering, though many problems may still be left to resolve in the field of humanities and social sciences. In the background to this gap between these two sector groups, probably some conflicts are lurking between the imported and native cultures.

National government policy for ARE in the postwar period

National government policy for academic research organization basically maintained the prewar structure from 1945, at the end of World War II, to 1990 when a market mechanism became clearly evident. Francis van Vught distinguished two types of national policy: national control and self-regulation (Van Vught 1989). According to these categories, the former operated exclusively throughout the history of higher education in Japan until 1990 when it was superseded by the latter with an accompaniment of much conflict. The phenomenon of "failure of the market" has been observable over recent years and so reconsideration of the current problematical situation is likely to become a focal point.

Akihiro Asonuma analyzed the postwar structure of funding in the national university over five periods: the end 
of World War II to 1955 ; 1956-1973; 1974-1980; 19811991; and 1992 to the present (Asonuma 2003, pp. 216223). Based on this analysis, the discussion below attempts to describe briefly the trend of national government policy for academic organization from 1945 to the present time; the current trends are discussed subsequently in Section "The impacts of the national government policies on ARE."

\section{The end of the World War II to 1955: formation of the postwar structure}

National government policy for the academic research organization in the postwar period paid attention mainly to re-construction of the devastated structure and function left by the war; strengthening the prewar structure provided a basis for the national universities. The concept of academic autonomy was increasingly strengthened as a result of government policy emphasizing the initiative of academic staff or academic staff groups. Consequently, a structure closed to society at large was firmly established at this time. Asonuma named it "the postwar structure in the research budget of the national university."

\section{6-1973: Development of the postwar structure}

In this period, government policy continued to increase the emphases already identified, while criticism and doubts about academic autonomy increased during the periods of campus turmoil lasting from 1960 to 1970 throughout the country. Social expectation of academic research was diminished by the violence and deficiencies evident in the campus turmoil.

\section{4-1980: Transformation I of the postwar structure}

In this period, the postwar structure could not cope with the rapid social change to the extent that university research organization began to decline. Allocations of research funds to individual academic staff began to decrease, though academic research subsidies from the Ministry of Education increased. In this period, it is recognizable that provision for big science began to be established outside the university, so that in this regard, the university was reduced to a marginal component in the total social research system.

\section{1-1991: Transformation II of the postwar structure}

Over this decade, national government policy for the organization of academic research, which had focused entirely on the national university, plunged into a new stage differing significantly from the previous policy. In particular, a market mechanism began to intrude in the form of change to the academic research budget and in private sources of funding.

A number of indicators showed this trend clearly and consistently. Allocation of funds to academic staff decreased; a change that devastated academic faculty in the national universities to the extent that it was called the "coffin of knowledge." Simultaneously funding through the special education and research budget was increased, though the non-competitive allocation to individual academic staff decreased rapidly. The academic research fund was increased but was accessible only on the basis of competition among researchers.

\section{To the present: transformation III of the postwar structure}

In the most recent years, operation of a market mechanism became even more evident, replacing that of the postwar structure and encouraging competition among universities. In general, this period is known as the age of education and teaching reforms-or even of revolution-in Japanese higher education. However, the national government focused its policy partly on the former and partly on the latter. In particular, it shifted from reform to revolution after 1995 when the science and engineering law was introduced to place priority on scientific and academic productivity.

In a move differing from those of transformations I and II, research funding for academic staff was increased. The large increase of funds for academic research was remarkable in this period and was derived from a continuous increase in the resources of the special education and research budget. The commercial economic depression restricted the possibility for any increase in private funding and there was little increase of funding for research institutes. A social demand for strengthening the ability to compete internationally resulted in a policy of promoting the sciences and engineering and brought about the science and engineering basic plan of 1996.

\section{The impacts of the national government policies on ARE}

Trend of the recent national government policy on ARE

In the last 10 years, the MEXT has introduced a corresponding series of policies and plans with an intended perspective: (1) the Jutenka policy, or a policy of selecting key graduate institutions in various fields of study; (2) the Science and Technology Basic Plan, which started in 1996; (3) the Toyama Plan which was issued by Atsuko Toyama, the minister of education in 2001; (4) the twenty-first 
century COE program in the area of research and the GP (Good Practice) program in the area of teaching and education, which were initiated in 2002; (5) the global COE program, which started from 2007, succeeding to the former twenty-first century COE program (2002-2007); and (6) establishment of the national university corporations in 2004. The effects of these national policies on the research universities have been great.

\section{Jutenka policy}

As the CEC pointed out in 2005, the trend of political change for graduate education, as a core part of ARE, has impacted upon both the institution and the organization. A number of clear trends can be identified: (1) an increase of a new type of graduate schools, such as universities providing graduate schools only (12 universities as of 2004); correspondence graduate schools (17 universities and 23 graduate courses); and part-time and evening graduate schools (22 universities and 28 graduate courses); (2) flexibility in conditions for enrollment and the length of graduate study; (3) reinforcement of teaching functions; (4) establishment of professional schools (93 universities and 122 courses as of 2005); (5) graduate schools linked to business and industry (105 universities and 206 graduate courses as of 2004); and (6) an increase of graduate students (from 87,476 in 1988 to 244,024 in 2004) (CEC 2005, pp. 4-5).

In addition to these polices, a national policy of Jutenka, which was introduced in 1991, is a policy of shifting the institutional emphasis from the members of faculty ( $\mathrm{ga}$ $k u b u)$ at undergraduate level to those (kenkyuka) in the graduate school level with provision of an additional 25\% of annual funding. The policy was adopted initially by the Faculties of Law in only two institutions, University of Tokyo and University of Kyoto. These two Faculties shifted their emphases from undergraduate to graduate level in 1991. Subsequently, all Faculties in these two institutions gradually underwent similar shifts over the 10 years to 2002. The other former imperial universities, the universities of Tohoku, Osaka, Kyushu, Hokkaido, and Nagoya, have now all followed suit in almost all Faculties with permission of the MEXT. Some of the other major research universities including Hitotsubashi University, Tokyo Kogyo University, University of Tsukuba, and Hiroshima University were also allowed to shift the weight of some Faculties to Graduate Schools. In implementing a process of Jutenka, three groups of institutions were differentiated: Jutenka with $25 \%$ additional funds; bukyokuka, or a false Jutenka without the $25 \%$ additional funds; and no Jutenka.

By this means, the graduate school has been promoted to an independent internal organization instead of being a subordinate organization to the undergraduate Faculty. Some 60 years after the postwar educational reform of 1945 , the separation of two tiers, which was nominally made then, has now been substantially realized. The shift of the graduate school to a research orientation is now established both nominally and substantially, although inevitably in the Japanese university a strong tendency toward a research orientation is retained at the undergraduate as well as the graduate level as was pointed out by Carnegie International Survey on Academic Profession (Altbach 1996; Arimoto and Ehara 1996).

\section{The Science and Technology Basic Plan}

A policy for a creative country with intensive promotion of scientific and technological productivity (Kagaku Gijutsu Souzou Rikkoku) was introduced accompanying the Science and Technology Basic Law (Kagakugijutsu Kihonhou), in 1995. Based on this law, the Science and Technology Basic Plan (Aiming at a nation based on the creativity of science and technology) was set up in 1996. "This plan was formed under the Science and Technology Basic Law (Act 130, Nov, 15, 1995), which was enacted to aim at a nation based on the creativity of science and technology. In order to encourage comprehensive and systematic policies for the promotion of science and technology, such as the promotion of scientific research activities at universities, the plan is formulated to materialize the science and technology five-year policy (from the fiscal year 1996 to 2000) with the following ten years in view" (MEXT 2006).

The first term lasted 5 years from 1996 to 2000, and the second term another 5 years from 2001 to 2005 . A third term has started from 2006 for a further period of 5 years. Governmental expenditure was prepared to finance each term by $¥ 17$, $¥ 22$, and $¥ 24$ trillion, respectively. It meant that money could be spent extravagantly directly on the plan and also indirectly on the research universities and research doctoral courses.

During these three terms, the amount of competitive funding has been extended dramatically. In FY 2000, the final year of the First Basic Plan period, the amount available was $¥ 296.8$ billion, or 2.4 times the amount in fiscal 1995, and in FY 2005, the final year of the Second Basic Plan period, the amount was $¥ 467.1$ billion, or 1.6 times the amount in fiscal 2000. These funds have fostered a competitive environment at R\&D sites (MEXT 2004).

\section{Toyama plan}

The Toyama plan is a policy focusing on three targets: (1) Pursuit of mergers and integration of national universities so as to decrease the number of national universities, with 
the aim of vitalization of the national universities by way of a policy of scrap and build; (2) Introduction of a private sector type of management into the national universities, leading to new national university corporations as soon as possible; and (3) Introduction of a competitively oriented principle into universities and colleges on the basis of a third party evaluation system to create a group of 30 top universities in national, public, and private sectors, able to be ranked among the top universities worldwide. In fact, this plan was introduced into a target for future in Basic Science and Technology in 2002, with a slogan of 30 Nobel Laureates in 50 years.

Putting greater priority on support for the research universities is perhaps the first stage in a series of national plans related to higher education reconstruction. As a result, it is pointed out that the national research universities have considerably increased their academic productivity, thanks to the government's advantageous treatment. In the process, some basic principles such as rationalization, efficiency, and accountability have been emphasized to ensure that funding was used as effectively as possible. Some provisions, including mergers, integrations, and restructuring of institutions were necessarily introduced to higher education institutions throughout the country. Especially, some single Faculty medical schools were asked to merge with other institutions such as adjacent comprehensive universities.

\section{The twenty-first century COE program}

The twenty-first century COE program, which was introduced in 2002, is a policy of constructing research bases that can attain worldwide competitiveness in academic productivity. According to JSPS, the number of programs selected were 113 in 2002, 133 in 2003, and 28 in 2004; the total funds invested in them were $¥ 17.6$ billion in 2002 , $¥ 15.8$ billion in 2003 , and $¥ 31.0$ billon in 2004 (JSPS 2006).

In the first year, for example, 113 of the 464 applicants were selected in five fields (life sciences, chemistry/material science, information sciences/electrical and electronic engineering, interdisciplinary/combined fields/new disciplines, and humanities) with support for their programs indicated to continue for 5 years from 2002 to 2007. The total amount of support for the first year, ¥17.6 billion Yen, was made available across a range of academic disciplines: life sciences, 28 centers including the national sector, 21, public sector, 1 , and private sector, 6; similarly 21 centers in chemistry/material science, including 18,0,3, in the national, public and private sectors respectively; 20 centers in information sciences/electrical and electronic engineering distributed 15, 0, 5, respectively; 24 centers in interdisciplinary/ combined fields/new disciplines distributed 17, 2, 5, respectively; and 20 centers in humanities distributed 13,1 , 6 , respectively. These bases were intended to be identified as the important research centers both inside and outside the academic world. Among the 113 programs, the national sector claimed the largest share 84 (74.8\%), followed by the private sector with $25(22.1 \%)$, and the public sector with 4 $(3.5 \%)$ (JSPS, ibid). The program sought to construct COE's in each field of discipline to increase its international competitiveness.

\section{The global COE program}

Started in 2007 as the modification of the twenty-first century COE program which lasted 5 years from 2002 to 2007, the new program covers the same five fields as the old one and puts more weight on graduate education to train capable researchers competitive enough for an international research environment. A similar philosophy is also observable in the third Science and Technology Basic Plan quoted below.

It is essential to develop capable researchers who enthusiastically pursue the creation of scientific knowledge and to promote their activities. If Japan produces world-class, capable researchers, they will be a good target for young human resources, and enthusiasm for new creation will be elevated. Therefore, the second basic plan set a goal of producing as many as 30 Nobel laureates in 50 years, aiming to increase the number of Japanese who win international prizes in science to the level of major European countries. (MEXT 2006)

In the first year of the new program, 63 of the 281 project applicants were selected in the five fields, with support for their programs indicated to continue for 5 years from 2007 to 2012. This can be expressed alternatively as 28 from 111 institutional applicants were selected. The total amount of support for the first year, $¥ 15.0$ billion, was made available across a range of academic disciplines.

The Table 3 shows the numbers of applicants and of their success by university sector. Among the 281 applicants as many as 200 , or $71 \%$, belong to the national sector, and among 63 successes as many as 50 , or $80 \%$, belong to the national sector. The strong bias in favor of the national sector is sustained. Notably, the strength of the former imperial universities (Teidai) is demonstrated by their success in obtaining 32 adoptions (51\%) from their 75 applications (27\%).

\section{The national university corporations}

A transformation of the national sector was realized in 2004 when 99 national universities were designated as the 
Table 3 Contents of application and adoption by university

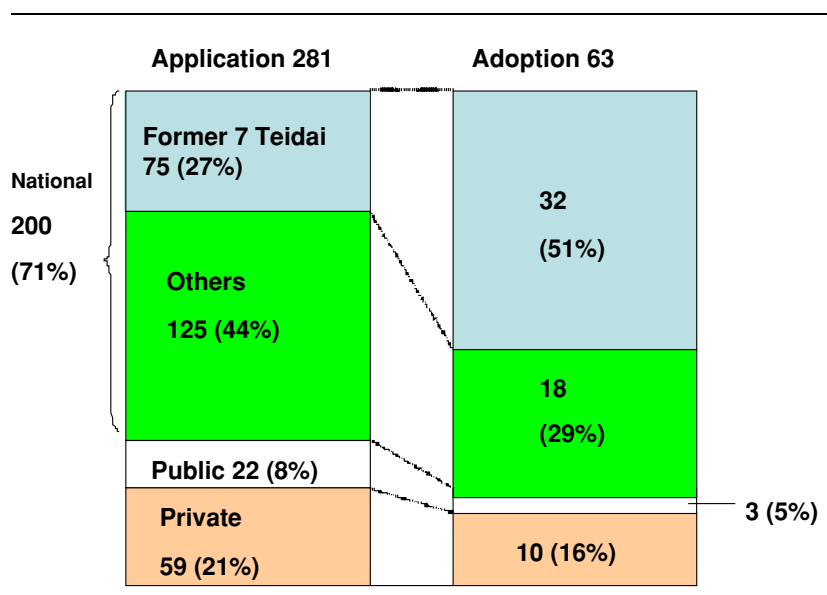

87 national university corporations. Their management was drastically changed from a bottom-up to a top-down mode by empowering the presidents and adding external representatives as members of the new trustee committees responsible for governance and management.

The radical change from the previous pre-evaluation by a chartering committee of the national government to a new post-evaluation system means an inquiry into the outcome of achievements related to each university's 6year plan. Additionally, the national government has started to allocate block funding to each university on the basis of its post-evaluation. Through this process, a differentiated society will begin to appear in accordance with the distinctions between the haves and the have-nots in higher education institutions.

Some unintended effects of the policies

As described above, a series of intensive research policies was implemented to establish the graduate schools, especially those in the research universities. However, it is recognizable that such policies have also brought about manifestly and latently some unintended negative aspects as well as the intended benefits. Some of these are discussed below.

\section{Unintended effects of the policy of Jutenka}

The policy of strengthening graduate schools, the policy of Jutenka, was expected to improve the quality of the national universities, and especially of the former imperial universities. As a result, it is clear that differentiation between the research universities and the non-research universities and even between the research universities themselves has been increased. The distinctions that had already emerged in the prewar period have become somewhat ambiguous, thanks to a series of national government policies in the postwar period nominally designed to realize equality among institutions. Nevertheless, the current policies, drastically emphasizing the differentiation between institutions, have turned out to evoke the differentiated society deliberately established by the national government in the prewar period.

\section{Negative sides of the Science and Technology Basic Plan}

As has already been discussed, the Science and Technology Basic Plan invested extensively in important fields of study by supporting designated research universities with a focus on specific advanced fields of study, particularly those related to the sciences, engineering, agriculture, and health. On the other hand, support was not increased so much in the fields of humanities and social sciences or to other relevant research universities. As a result, basic research has not developed as well in comparison to applied and developmental researches.

\section{Effects of the Toyama Plan}

The Toyama Plan brought about an institutionalization of the national university corporation and has decreased the research funds available for internal allocation to faculty members in each institution. In the former national universities, faculty members received an allocation automatically from the national government without any control or filter at the governance level of the president and trustees. In contrast, in the new system, allocation of the block grant is undertaken at the level of governance so that faculty members will receive allocations distributed competition.

There are several categories of chair identified in universities and colleges for the purposes of determining the amount of research funding allocated: a diagnosis chair (rinsho-koza); an experimental chair (jikken-koza); and a non-experimental chair (hi-jikken-koza). Under the new provisions, reclassification of faculty members as researchers has forced some to move from experimental chairs to non-experimental chairs, with substantial changes to their funding. There are great differences, approximately a factor of three, in the total amount of support allocated to an experimental chair and a non-experimental chair.

In addition, it is though rather easier to get competitive funds in the field of natural sciences than in the field of humanities and social sciences. Accordingly, the differentiation between these two sectors has necessarily considerably increased. For example, according to a study of research funding allocation among individual academic staff and institutions, differentiation has developed within recent 15 years. Introduction of competitive type funding, 
basic research funding decreased two-thirds, though competitive funding per a individual academic staff has increased three times. In the increasing differentiated academic society, status mobility is less invisible in the upper status group, while visible in the middle and lower status groups in terms of individual academic staff and also individual institutions (Hiroo Urata 2008).

\section{Emergence of differentiation between the research university and the non-research university}

The series of national policies which had been implicitly practiced for many years during the postwar period, has, in recent years, become explicit and evident. These policies are now related to an international environment of competition among institutions in which every country seeks to achieve a peak of academic institutional stratification at a worldwide COE level. COE programs to do this can be recognized in Asian countries, including China, South Korea, as well as Japan (Altbach and Umakoshi 2004).

In this context, the twenty-first century $\mathrm{COE}$ program has brought about great differences in access to research funds between research and non-research universities. Among the former are those universities that were successful in achieving greater visibility and prestige in scientific and academic society and also in society at large. For example, in Japan, University of Tokyo, which was selected as a COE institution in a number of areas, has become uniquely powerful and visible.

\section{Discussion of proposals for reform}

Reform of ARE in the context of the research university has exposed many problems. In the Japanese research university, much effort was expended in catching up with the research systems of advanced countries over more than a century. As a result, the research university could successfully match the achievements of centers of learning elsewhere in the World in some disciplinary fields. However, overall the gap between the COE of the World, the U.S., and Japan is still considered to be great. One of the reasons probably originates from insufficient preparation of policies, plans, and reforms in connection with the institutionalization and enhancement of graduate education, even though it has been rapidly promoted in recent years (Clark 1995). We identify some other problems that need to be dealt with in the following discussion.

\section{Construction of academic research policy}

As already mentioned, the national government proposed new academic research policies successively in 1998 and 2004, promoting the priority accorded to the research university and its graduate education (UC 1998; Arimoto 2005c; CEC 2005). These policies have generated a number of additional problems. In considering the international dimension, an academic system capable of responding to worldwide competition in academic productivity is needed. As has been described, the reformed centers of academic learning were built on the base of the former imperial universities and so more support was provided to these established institutions to raise further their competitive abilities. Formation of the array of COE institutions and other universities was determined by a series of policies. On the basis of the traditional research institutions, which had existed since the prewar period, the COE institutions were developed by a combination of the twenty-first century COE program, the Science and Technology Basic Plan, and the GP program. It is though noticeable that these policies stress the advanced sciences to raise a peak of key institutions, while the necessity of expanding the range of basic research is also needed.

\section{Allocation of funds}

Recent policies have paid much more attention to the fields of natural sciences, engineering, agriculture, and medicine than to the fields of humanities and social sciences. It is true to say that in Japanese, graduate schools the areas of humanities and social sciences have been neglected in their development in comparison with the areas of sciences, engineering, and medicine in terms of the number of doctoral degrees, the quantity and quality of academic productivity, and the exchange and mobility of researchers among institutions (cf. Clark 1993, 1995). Of course, both fields are important for the development of academic studies and learning, and more consideration should be paid to the humanities and social sciences if the differences between the two fields are not to be expanded.

\section{A correction of the university gap}

From an international comparison, the hierarchy of Japanese higher education institutions is seen as a steep-stratified structure rising to a pinnacle (Clark 1983). Transformation from this narrow pinnacle to a mountain range with several peaks is expected to be created so as to realize a better chance of effective competition among institutions.

\section{Balance between the sciences and the humanities and social sciences}

The fact of the increase of differentiation between these two sectors derives from the gap in resource allocation among and within the institutions. It is understandable that the expensive science sector needs much greater funds than 
the humanities and social sciences, but the widening differences in funding between the two sectors causes a crisis of decay of researchers in humanities and social sciences and also of the research graduate schools. The consequent decay will in the long run impose fundamental constraints not only on the development of learning but also for the development of society itself.

\section{Construction of an evaluation system}

Third party evaluation processes have usually worked on the basis of peer review and such a mechanism is expected to be employed in the newly introduced institutional accreditation system. JABEE (the Japan Accreditation Board for Engineering Education), which was established in 1999, is a nongovernmental organization that examines and accredits programs in engineering education in close cooperation with professional engineering associations and societies. Procedures similar to those used by JABEE are to be considered in other areas so as to raise their academic productivity and quality of teaching to an international standard.

\section{Reconsideration of scholarship}

In the twenty-first century, it is necessary for us to seek an integration of research, teaching, and learning by reconsidering the role of scholarship. According to the Carnegie International Survey on the Academic Profession in 1992, Japanese academic staff showed a much stronger orientation to research than to teaching, and correspondingly a rather weak orientation to learning (Altbach 1996; Arimoto and Ehara 1996). In connection to this matter, there are two problems to be resolved as soon as possible. One is related to students and provision of a prefaculty development program (pre-FD). In doctoral programs, the outcome from teaching, in at least this respect, has been insufficient. There has been little development of a pre-FD program that should be incorporated in graduate education. This failure is not necessarily restricted to the Japanese context. For example, Harvard University's Task Force on General Education noted that "The more varied their teaching experience is during graduate school, the more resourceful and effective our PhD students will be when they develop courses of their own as professors" (Harvard University 2006, p. 38). In this context, the accountability of doctoral programs should be questioned as seriously in teaching as in research. A traditional research orientation prevails to the extent that graduate students are not prepared for teaching in universities and colleges after their graduation. This tradition should be reformed.

The second is related to faculty members. Based on Boyer's concept, an integration of research and teaching should be realized as soon as possible (Boyer 1990).
However, for the next stage of FD, at the level of theory and practice in the twenty-first century, a component of learning should be included in the composition of scholarship by which an integration of research, teaching, and learning can be established to replace the integration of research and teaching (Clark 1995; Nicolls 2005).

\section{Concluding remarks}

The discussion has sought to identify some problems for the ARE, particularly the enterprise of Japanese research graduate schools.

First, the research university enterprise in Japan was delayed in its development compared to its counterpart in the West-and especially in the U.S.-due to the delayed establishment of a graduate school system. As a result, it is now hurriedly pursuing reforms of its graduate schools. It is clear that the reforms have made great progress in regard to the research universities, academic staff, non-academic staff, students, and funding.

Second, the research university enterprise imported foreign models and pursued academic reforms so as to catch up with centers of learning elsewhere in the world. In the prewar period, the concept of the research graduate school was not well developed, because the selected German model had no graduate school. Accordingly, research developed under a traditional chair system at undergraduate level. A few of the then imperial universities, with "organizing chair systems" assumed the roles of research universities, and constituted an elite system in the development of higher education.

Third, in the postwar period, higher education itself shifted from an elite stage to a massified stage for which an American university model was imported. Based on the former imperial universities of the prewar period, several research universities were deliberately developed in accord with a graduate school system. The graduate school developed smoothly in the field of sciences though in the field of humanities and social sciences it achieved little development and an undergraduate-centered structure persisted, just as in the prewar period.

Beyond the 1990s, higher education policy sought to strengthen graduate education and invested much funding in its development. As a result, differentiation between the research university and the non-research university extended considerably. At the same time, an institutional hierarchy in the stratification of research universities rapidly increased. A further differentiation of stratification between the sciences and the humanities and social sciences was added to that at institutional level.

Fourth, the research university enterprise must respond to social changes as well as to a logic of academic study to realize its proper development. In other words, it has to 
accommodate social changes such as knowledge-based society, globalization, and market mechanisms and also structural change in relation to reconstruction of knowledge. In this context, it faces key problems of realizing social imperatives at the same time as accommodating reconstructed knowledge (Arimoto 2008).

These problems are clearly related to the derived issues of higher education policy, governance, administration, and management of the university institution and organization, quality assurance of academic work in the research university enterprise, and reconstruction of the academic profession. How academic reform is best pursued is an issue whenever we attempt to coordinate the external pressures from outside academia and the internal pressures from inside academia.

Fifth, this article has sought to analyze the ARE, particularly the research university enterprise in Japan. Based on these tentative observations of research university enterprise in Japan, it is clear that-as with all good research-more study is needed to yield the greater detail that would fully enrich the given theme from an international comparative perspective.

Open Access This article is distributed under the terms of the Creative Commons Attribution Noncommercial License which permits any noncommercial use, distribution, and reproduction in any medium, provided the original author(s) and source are credited.

\section{References}

Altbach, P. G. (1996). The international academic profession: Portraits of fourteen countries. Princeton: Carnegie Foundation for the Advancement of Teaching.

Altbach, P. G., \& Umakoshi, T. (Eds.). (2004). Asian Universities: Historical perspectives and contemporary challenges. Baltimore \& London: The Johns Hopkins University Press.

Amano, I. (1984). Method of university classification. In T. Keii (Ed.), Daigaku Hyoka no Kenkyu (Study of University Evaluation). Tokyo: University of Tokyo Press.

Amano, I. (1986). Koto Kyoiku no Nihonteki Kozo (Japanese structure of higher education). Tokyo: Tamagawa University Press.

Amano, I. (2006). Daigaku Kaikaku no Shakaigaku (Sociology of University Reform). Tokyo: Tamagawa University Press.

Arimoto, A. (1987). Study of Merton sociology of science: Formation and development of its paradigm (in Japanese). Tokyo: Fukumura Publishing Co.

Arimoto, A. (Ed.). (1996). Study of center of learning. Tokyo: Toshindo Publishing Co.

Arimoto, A. (2002). Globalization and higher education reforms: The Japanese case. In J. Enders \& O. Fulton (Eds.), Higher education in a globalising world (pp. 127-140). Dordrecht: Kluwer Academic Publishers.

Arimoto, A. (2003). Recent higher education reforms in Japan. In Higher Education Forum (Vol. 1, pp. 71-87). Hiroshima: Research Institute for Higher Education, Hiroshima University.

Arimoto, A. (2005a). Globalization, academic productivity, and higher education. In A. Arimoto, F. Huang, \& K. Yokoyama (Eds.), Globalization and higher education (pp. 1-21) (RIHE
International Publication Series, No.9). Hiroshima: Research Institute for Higher Education, Hiroshima University.

Arimoto, A. (2005b). Structure and function of financing Asian Higher Education (pp. 176-187). Higher Education in the World 2006, UNESCO-GUNI.

Arimoto, A. (2005c). National Research Policy and Higher Education. Journal of Educational Planning and Administration (pp. 175198). New Deli, India: National Institute of Educational Planning and Administration.

Arimoto, A. (2007). National Research Policy and Higher Education reforms with focus on Japanese case. In S. Sorlin \& H. Vessuri (Eds.), Knowledge society vs. knowledge economy: Knowledge, power, and politics (pp. 175-197). New York: Palgrave Macmillan.

Arimoto, A. (2008). Chishiki Souzou Hassingata no Koutou Kyouiku (Knowledge creative and export type higher education). Reviews in Higher Education, No. 99, July 2008 (pp. 17-41). Hiroshima: Research Institute for Higher Education.

Arimoto, A., \& Ehara, T. (Eds.). (1996). International comparison of academic profession (in Japanese). Tokyo: Tamagawa University Press.

Asonuma, A. (2003). Sengo Kokuritsudaigaku niokeru Kenkyuhihojo (Research budget subsidy at National University in Post-War period). Taga Publishing Co.

Becher, T. (1981). Towards a definition of disciplinary cultures. Studies in Higher Education, 6, 109-122. doi:10.1080/030750 78112331379362.

Becher, T. (1989). Academic tribes and territories: Intellectual enquiry and the cultures of the disciplines. Milton Keynes: Open University Press.

Becher, T., \& Trowler, P. R. (2001). Academic tribes and territories: Intellectual enquiry and the cultures of the disciplines (2nd ed.). The Society for Research into Higher Education \& Open University Press.

Ben-David, J. (1977). Centers of learning. New York: McGraw-Hill.

Bleiklie, I., \& Henkel, M. (Eds.). (2005). Governing knowledge: A study of continuity and change in higher education: A Festshrift in Honor of Maurice Kogan. Dortrecht: Springer.

Boyer, E. L. (1990). Scholarship reconsidered. Princeton: Carnegie Foundation of the Advancement of Teaching.

Carnegie Commission on Higher Education. (1976). A classification of higher education.

CEC (Central Education Council). (2005). Wagakuni no Koto Kyoiku no Shouraizou (Future Vision of Higher Education in Japan). Tokyo: Central Educational Council.

Clark, B. R. (1983). Higher education system: Academic organization in cross-national perspective. Berkley: University of California Press.

Clark, B. R. (Ed.). (1993). The research foundations of graduate education: Germany, Britain, France, United States, Japan. Berkeley: University of California Press.

Clark, B. R. (1995). Place of inquiry. Berkley: University of California Press.

Council of Science, Engineering, Human Resources. (2002). Sekai Top Class no Kenkyusha Yousei nimukete (Toward Training World Top Class Researchers).

Gibbons, M., Nowotny, H., Limoges, C., Schwartzman, S., Scott, P., \& Trow, M. (1994). The new production of knowledge: The dynamics of science and research in contemporary societies. London: Sage Publications.

Harvard University. (2006). Faculty of Arts and Sciences. Preliminary Report, Task Forces on General Education, October, 2006.

JASSO (2006). Enhancement of scholarship project.

Jiao Tong University. (2007). Academic ranking of World Universities.

JSPS. (2006). Overview of COE program.

JSPS. (2007). JSPS Research Fellowships for Young Scientists. 
Keidanren. (2007). Daigakuin Hakasekatei no Genjou to Kadai: Intermediate Report (pp. 1-12) (Present Situation and Problems of Doctoral Course of Graduate School: Chukan Hokoku). Tokyo: Nippon Keidanren, Sangyou Gijutsu Iinkai.

Kobayashi, M. (2005). "Sekai Daigaku Ranking no Hikaku" (Comparison of Academic Ranking of World Universities). Shigaku Koto Kyouiku Kenkyu Sosho (pp. 1-50). Tokyo: Shigaku Koto Kyoiku Kenkyusho (Research Institute for Private Higher Education).

Light, D. R. (1974). Introduction: The structure of the academic profession. Sociology of Education, 47, 2-28. doi:10.2307/211 2165.

Maassen, P., \& Cloete, N. (2006). Global reform trends in higher education. In N. Cloete, P. Maassen, R. Fehnel, T. Moja, T. Giccon, \& H. Perold (Eds.), Transformation in higher education: Global pressures and local realities (pp. 7-33). Dordrecht: Springer.

Merton, R. K. (1973). In N. Storer (Ed.), The sociology of science: Theoretical and empirical investigations. Chicago: Chicago University Press.

MEXT. (2004). Annual report on the promotion of Science and Technology, FY 2004.

MEXT. (2006). Annual report on the promotion of Science and Technology, FY 2006.

MEXT. (2007). White paper on Science and Technology, FY 2007.

MEXT. (2008). Gakko Kihon Chosa (Basic School Survey), FY 2008.

Nakayama, S. (1978). Teikoku Daigaku no Tanjo (Birth of Imperial University). Tokyo: Chuou Koronsha Publishing Co.
Nicolls, G. (2005). The challenge to scholarship: Learning, teaching, and research. London and New York: Routledge.

NIPSSR (National Institute of Population and Social Security Research) (Kokuritsu Shakai Hosho - Jinkou Monadai Kenkyusho). (2004). Nippon no Jinko Suikei 2001-2050. Population Projections for Japan: 2001-2050, Home Page. Tokyo: National Institute of Population.

Parry, S. (2007). Disciplines and doctrates. Dordrecht: Springer.

Rissanen, J., \& Viitanen, J. (2001). Report on Japanese technology. Tokyo: The Finish Institute in Japan.

Shinbori, M. (Ed.). (1985). Gakumon Gyoseki no Kouka: Kagaku no Eponymy Gensho (Evaluation of Academic Achievement: Eponymy Phenomena in Science). Tokyo: Tamagawa University Press.

Sorling, S., \& Vessuri, H. (2007). Knowledge society vs. knowledge economy: Knowledge, power, and politics. New York: Palgrave Macmillan.

Spiegel-Rosing, I., \& de Price, D. S. (1977). Science, Technology and Society: A cross-disciplinary perspective. London and Ververly Hills: Sage Publications.

UC (University Council). (1998). 21 seiki Daigaku Kaikak no Rinen to Hoko (21st University vision and direction for reforms). Tokyo: University Council.

Urata, H. (2008). "Kenkyuhi no Haibun" (Allocation of research expense). In A. Arimoto (Ed.), Changing academic profession in Japan (pp. 160-174). Tokyo: Tamagawa University Press.

Van Vught, F. A. (1989). Governmental strategies and innovation in higher education. London: Jessica Kingsley. 